\title{
INTERVENCIONISMO DE LOS MEDIADORES EN LAS TRADUCCIONES DE LITERATURA INFANTIL Y JUVENIL ALEMANA
}

\author{
Veljka Ruzicka Kenfel \\ Universidade de Vigo
}

\begin{abstract}
When dealing with interventionism of mediators, we are talking about the factors that have an influence in the intended or not manipulation of the source texts. In this paper, we would like to point out that the distance of the translation in relation to the source text is sometimes allowed, in particular if we are dealing with Children's Literature. This is due mainly to three factors: Linguistic politics of the receptor text's community, the pressure of institutions such as teachers or editors that have a strong influence in the decisions taken by the translator and finally the double receptor children-adult.
\end{abstract}

\section{INTRODUCCIÓN.}

El intervencionismo de los mediadores ha sido analizado y estudiado en muchas ocasiones, sobre todo desde la perspectiva polisistémica. Los estudios polisistémicos tratan en conjunto fenómenos de lengua, literatura y cultura y son aplicables en los análisis de traducciones literarias en comunidades donde conviven dos o más lenguas en conflicto y donde la política lingüística orienta determinadas opciones. Han desarrollado el concepto de normas, como conjunto de posturas que definen el comportamiento traductor de una determinada época y en un contexto socio-histórico y cultural concreto. En ningún caso se debe entender aquí la noción de normas como reglas de traducción, con la carga prescriptiva a la que uno está acostumbrado, sino como regularidades que se observan en un contexto dado en el comportamiento de los traductores. Se pueden definir, según los estudios polisistémicos, tres tipos de normas. La norma inicial se entiende como la elección primaria que el traductor hace, bien buscando la extranjerización (Verfremdung) de su traducción, adecuándose a las normas de texto origen, bien persiguiendo una traducción domesticada (Einbürgerung) que siga los modelos ya existentes en la cultura meta.

Las normas preliminares reflejan la política editorial de traducciones, dominante en la comunidad receptora y la política lingüística programada desde el poder. Este tipo de normas pretende aclarar algunas cuestiones como, por ejemplo, cuáles son los textos elegidos para traducir; cuáles son los autores que se traducen; cuáles son las lenguas de procedencia de los originales; cuál es el perfil del traductor; cuál es la posición del traductor con respecto a su traducción en aquellos casos donde en la comunidad receptora convive otra cultura u otra lengua con más influencia; cuál es el grado de tolerancia social cara a las traducciones indirectas (hechas desde lenguas intermedias).

Y por último, las normas operacionales son decisiones tomadas en el mismo proceso de la traducción. Con ellas se observa si la traducción respeta la variedad de la lengua 
correspondiente al corte sincrónico del original o si, más bien, se adecua a la variedad existente en el momento de la publicación. Sobre todo se contemplan aquí los elementos lingüístico-textuales que se refieren a la selección de segmentos morfosintácticos, léxicosemánticos, grafo-fonológicos y estilísticos que el traductor emplea.

Dichas normas representan una cierta regularidad en la toma de decisiones del traductor que, como miembro de una comunidad concreta, actúa como se espera de él y sigue los principios traductores de su época y de su contorno específico.

Siguiendo las pautas de esta teoría polisistémica, pretendemos apuntar la necesidad de crear sistemas evaluativos de cada intervención con respecto al texto origen, porque en muchos casos de literatura infantil y juvenil (LIJ) las manipulaciones se pueden considerar justificables, permisibles e incluso aconsejables debido a la existencia de determinados factores, entre los que cabe citar especialmente tres: el doble receptor niño-adulto; la política lingüística de la comunidad receptora del texto meta; y la presión de la institución, es decir, de todos aquellos terceros que influyen en la toma de decisiones del traductor (padres, educadores, editoriales).

\section{DOBLE RECEPTOR NIÑO-ADULTO E INTERVENCIONISMO DE LOS TRADUCTORES.}

La naturaleza del receptor de LIJ, sujeto a los cánones sociales impuestos por los adultos y condicionado por su capacidad receptora todavía reducida con respecto a las referencias desconocidas, da lugar a una característica específica de este subsistema literario, que se define como asimetría de la comunicación porque el mediador adulto interviene en todos los procesos de la producción literaria, ajustando el producto a las necesidades de la edad del receptor. Esta desigualdad en la competencia lectora origina la existencia de diferentes tipos de lector y niveles de lectura de un texto de literatura infantil': si el adulto es el destinatario principal, su función es la de ejercer una postura crítica desde su perspectiva del lector experimentado; si el adulto se presenta como lector secundario (Mitleser), ejercerá de mediador e intentará formar un juicio sobre el texto desde el punto de vista del receptor infantil; en el siguiente nivel de lectura se sitúa el niño/adolescente que, como el adulto, tiene una doble función: como lector legitimado (sanktionierter Leser), es decir, receptor de textos preparados para él y autorizados por las instancias mediadoras; y como lector no legitimado (nicht sanktionierter Leser), esto es, consumidor de textos que no forman parte del canon literario y no han obtenido el visto bueno de los censores pedagógicos. La existencia de estos cuatro tipos de lector de un mismo texto determina la sistematización de textos literarios infantiles y juveniles en dos grupos. En el primero se sitúan los systemeindeutige Texte, propios del subsistema literario infantil/juvenil, y en el segundo los ambivalente (doppelbödige / doppelsinnige) Texte, porque tienen dos lectores con competencia lectora diferente, ya que sus elementos admiten varias interpretaciones, siempre dependiendo del grupo receptor que realiza la lectura, aunque su destinatario principal es el adulto.

' H. H. Ewers, Literatur fïr Kinder und Jugendliche. Eine Einführung, München, Fink, 2000. 
En la traducción de un texto de LIJ, la asimetría comunicativa es aún más manifiesta porque el traductor actúa como un nuevo mediador, aparte del escritor y editor. Él, como lector implícito, decide cuál es la manera más acertada de acercar el texto al receptor de su cultura. En muchos casos, sus decisiones vienen condicionadas por varios factores: por el contexto sociolingüístico de la cultura de llegada, por la capacidad receptora del niño y por el valor de las normas impuestas por la sociedad adulta. Estos factores le ofrecen más libertad de manipulación, con lo cual se minimiza el sentido de respeto hacia el texto original, una circunstancia que nunca o pocas veces ocurre con las traducciones de un clásico para adultos, donde el traductor reduce al máximo su presencia para poder reflejar con mayor fidelidad la idea del autor original.

El intervencionismo del traductor como mediador se observa sobre todo en los textos ambivalentes que suelen tener traducciones para cada tipo de lector implícito. Respecto a la LIJ alemana basta observar las numerosas y muy diferentes traducciones de Heidi (en España, aproximadamente sesenta) para constatar que muchas de ellas se han convertido en una simple literatura de aventuras que proporciona una lectura fácil y complace los deseos triviales, sin reflejar el complejo trasfondo del original, como puede ser la difícil situación social de la población rural suiza con la llegada del capitalismo y la imagen decadente de la civilización urbana. Este es el caso de algunos títulos, como Las bellas historias de Heidi; El mundo maravilloso de Heidi; Heidi, llegada a los Alpes; Otra vez Heidi o la adaptación gallega que en forma de cómic enseña cómo aprender el inglés a través de las aventuras de la protagonista.

Del libro Momo, ein Märchenroman de Michael Ende aparece en España en 2002 una adaptación basada en la película Momo. Una aventura a contrarreloj, que transforma el género de la novela-cuento de hadas de Ende en una historia ilustrada de persecución con características detectivescas. La mayoría de las adaptaciones no permiten entrever las continuas referencias del escritor al romanticismo alemán, como por ejemplo, la presentación del niño como portador de valores positivos. Momo es el símbolo "des EwigKindlichen im Menschen", según las palabras de Ende, y no de un niño o una niña en concreto. Su imagen por ello siempre aparece de espalda y nunca se permite descubrir su rostro. En las diferentes traducciones españolas, sin embargo, Momo se revela como una niña sonriente y de grandes ojos castaños y deja de simbolizar "lo eterno infantil dentro del hombre".

El intervencionismo de los mediadores de manera intencionada a favor de la cultura meta es manifiesta también en la traslación de los aspectos emancipadores que pueden transmitir textos literarios originales, pero que en la cultura de llegada realmente son temas tabúes con lo cual se intenta suavizar su impacto. Entre estos aspectos destacan las relaciones amorosas y familiares, los problemas de la adolescencia y el lenguaje vulgar. El concepto de emancipación cambia de una cultura a otra. Así, por ejemplo, el tema de la homosexualidad no representa una novedad en la literatura infantil y juvenil alemana porque fue introducida ya en los años noventa. En 1994, se publican dos libros con argumentos similares: Leanders Traum de Doris Meissner-Johannknecht, donde se relata el amor de una madre soltera por otra mujer, y Papas Freund de Michael Willhoite, en el cual el autor retrata la imagen de una mujer moderna que, aunque abandonada por su marido, no se desespera de la situación e intenta explicar a su hijo que su padre ahora tiene un novio, 
algo nada extraño porque "Schwulsein ist nur eine andere Art von Liebe...". Efectivamente, el hijo (y a través de él, probablemente, el lector infantil/adolescente) acepta esta circunstancia de manera espontánea. Pero, ¿serán asimilados estos contenidos emancipadores en otras culturas, como puede ser la española, con la misma naturalidad? En España, por el momento, no se traducen libros infantiles que contienen esta temática porque el mediador adulto (traductor, editor) todavía considera que su efecto puede ser contraproducente y su contenido provocar incomprensión y confusión.

Por otro lado, se observa que hay obras de LIJ alemana que, por temor a provocar conflictos entre el joven lector y las estructuras sociales existentes en su cultura, han sido traducidas con bastante posterioridad a la obra original y que en ellas han sido pulidos o suavizados los elementos supuestamente perjudiciales. Un ejemplo de ello es la novela adolescente Ilse Janda, 14 de Christine Nöstlinger, que ha sido traducida al español trece años después de su publicación en alemán (1974) con el titulo Ilse se ha ido (1987). Ilse es una adolescente que está en continuo conflicto con sus padres, conservadores y autoritarios. Está enamorada de Wolfgang y sueña con estar con él y sentir su cuerpo. Precisamente, las descripciones de contactos corporales y los deseos de Ilse han perdido su fuerza emotiva y el poder erótico en la traducción española: "Ilse sehnt sich nach Wolfgang" se transforma en "Ilse echa de menos a Wolfgang" ("Ilse vermisst Wolfgang"), el sueño erótico se convierte en el sueño romántico. Es evidente que resulta difícil encontrar un verbo en español con la misma carga semántica que contiene "sich sehnen", no obstante, su repetición reiterada en la obra original tiene un claro propósito de la autora de provocar una sensación pasional en el lector. Este impacto no se logra con la repetición de "lo echa de menos", porque el efecto que produce resulta más neutral e indiferente.

En algunos casos, el intervencionismo intencionado consiste en "corregir" o cambiar el sentido de las expresiones consideradas vulgares e inadecuadas para el público infantil/juvenil, con el único propósito de conseguir su aceptabilidad en la cultura meta. La anorexia y la prostitución, a las que se refiere en dos ocasiones Nöstlinger en su obra Olfi Obermeier und der Ödipus (1984), son términos censurados en la traducción española (Olfi y el Edipo, 1987):

Nur ein Verdacht auf Magersucht! (p. 66)

¡Flaca! (p. 65)

En el siguiente ejemplo ni hay alusión a la prostitución ni se mantiene el tono vulgar del texto original:

"die gehen nämlich - laut Oma - auf den Strich." (p. 52)

"se pasan de la raya". (p. 52) ${ }^{2}$

\footnotetext{
${ }^{2}$ Para un estudio más amplio véase: G. Marcelo Wirnitzer, "Verschiedene Arten von Domestizierung bei Übersetzungen von Büchern von Christine Nöstlinger ins Spanische", en: V. Ruzicka Kenfel, Kulturelle Regionalisierung in Spanien und literarische Übersetzung. Studien zur Rezeption deutschsprachiger KJL in den zweisprachigen autonomen Regionen Katalonien, Galicien und Baskenland, Frankfurt a.M., Peter Lang, 2002, p. 97-109.
} 
Los aspectos que quizás más se descuidan en la traducción de LIJ alemana son los literarios. Uno de ellos es la intertextualidad que, como procedimiento estético, opera de manera fructífera cuando se trata de introducir vías interpretativas destinadas a los adultos. Se emplea en forma de citas, referencias directas u observaciones irónicas y produce normalmente un efecto cómico. La intertextualidad, como guiño al adulto, no siempre se resuelve de manera satisfactoria a la hora de trasladarla a la otra cultura. Este descuido se debe básicamente a los insuficientes conocimientos literarios del traductor con respecto a la lengua origen, como lo pueden demostrar los siguientes ejemplos ${ }^{3}$. La traductora de la obra Wir pfeiffen auf den Gurkenkönig (1972) de Christine Nöstlinger no ha sabido trasladar la alusión de la autora al cuento de los Grimm Die Bremer Stadtmusikanten, probablemente porque no lo conoce y consecuentemente ignora que "der unterste Teil von den Bremer Stadtmusikanten" es el burro:

„Aber die Mama hat erklärt, dass der Nik ja auf ihrem Scho $\beta$ sitzen muss und dass sie etwas dagegen hat, wenn da auch noch der Gurkinger draufsitzt, weil sie nicht der unterste Teil von den Bremer Stadtmusikanten ist" (p. 30).

Traducción (Me importa un comino el rey pepino, 1984):

„Pero mamá declaró que Nik tenía que ir sentado encima de ella y que ella sí ponía reparos a que encima de Nik fuera el rey pepino, porque ella no estaba dispuesta a cargar hasta con la Banda Municipal de Bremen“ (p. 32)

En el siguiente ejemplo se trata de las traducciones de la trilogía Gretchen Sackmeier (Gretchen Sackmeier - Eine Familiengeschichte (1981); Gretchen Sackmeier hat Hänschenkummer (1983); y Gretchen mein Mädchen (1988)), también de Nöstlinger. Ninguna de las traductoras de los tres tomos ha sabido interpretar la intención de la autora de mantener textualmente el mismo prólogo en cada libro y cambiar únicamente la edad de la niña, sobre cuya evolución personal trata la trilogía. Al no respetar la traducción española la alusión de la autora a los tomos anteriores y al no repetir el mismo texto inicial, se obtienen como resultado tres libros independientes. Con ello también se ha perdido la referencia indirecta de Nöstlinger a muchos libros de la literatura alemana del siglo XVIII cuyos capítulos se inician con un título-resumen. Las traducciones tampoco permiten descubrir la alusión de la autora a los Mädchenromane de finales del siglo XIX:

Gretchen Sackmeier - Eine Familiengeschichte (1981)

\section{Kapitel}

welches noch keine größeren Ansätze zur Handlung zeigt, sondern nur fünf Säcke eingehend -und dies auch aus Sicht der Nachbarn -beschreibt.

Margerethe Maria Sackmeier, Gretchen genannt, war 14 Jahre alt und hatte donaukieselgraue Augen, spanielbraune Haare und eine winzige Babynase. Sie war $1,60 \mathrm{~m}$ groß und wog 64 Kilo und 300 Gramm.

Una historia familiar (1985)

\footnotetext{
${ }^{3}$ Para un estudio más amplio véase M. Fischer, "Konrad, Pinocchio y Edipo: la intertextualidad en la traducción de la literatura infantil", en: L. Lorenzo, A. Pereira, V. Ruzicka (ed.), Contribuciones al estudio de la traducción de literatura infantil y juvenil, Madrid, CIE. Dossat 2000, 2002, p. 43-69.
} 


\section{Capítulo 1}

en donde aún no aparece el menor asomo de acción, sino sólo la descripción detallada de 5 sacos, y ello desde la perspectiva de los vecinos.

Margarethe María Sackmeier, conocida como Gretchen, tenia 14 años y ojos del color gris de los guijarros del Danubio, cabellos castaño cocker y una diminuta nariz respingona. Medía 1 m y 60 centimetros y pesaba 64 kilos y trescientos gramos.

Gretchen hat Hänschenkummer (1983)

1. Kapitel

in weichem die Handlung noch keinen Lauf nimmt, sondern bloß versucht wird, dem geneigten Leser, der Band 1 der Geschichte nicht kennt, die Heldin der Handlung nahezubringen.

Margerethe Maria Sackmeier, Gretchen genannt, war 15 Jahre alt und hatte donaukieselgraue Augen, spanielbraune Haare und eine winzige Babynase. Sie war $1,66 \mathrm{~m}$ groß und wog 53 Kilo.

Gretchen se preocupa (1986)

Capitulo 1

en el cual aún no se pone en marcha el argumento, sino que simplemente se intenta que el amable lector que no conoce el tomo 1 de la historia se aproxime un poco a la heroína del argumento.

Margarethe Maria Sackmeier, llamada Gretchen, tenía 15 años de edad, ojos de un tono gris profundo como las piedras de un río, el cabello castaño claro y una diminuta nariz de bebé. Medía $1 \mathrm{~m} 66$ centímetros de altura y pesaba 56 kilos.

Gretchen mein Mädchen (1988)

\section{Kapitel}

das dem geneigten Leser, welcher Band 1 und Band 2 der Geschichte nicht kennt, die Heldin der Handlung nahezubringen versucht.

Margerethe Maria Sackmeier, Gretchen genannt, war 17 Jahre alt und hatte donaukieselgraue Augen, spanielbraune Haare und eine winzige Babynase. Sie war 1,70 m groß. Ihr Leib war, in voller Länge, wohlgeformt.

\section{Gretchen mi chica (1991)}

\section{Capitulo 1}

en el que se intenta presentar a la protagonista al amable lector que no conoce los tomos 1 y 2 de la historia.

Margarethe María Sackmeier, apodada Gretchen, tenía 17 años, ojos grises como los cantos de un río, cabello castaño claro y una diminuta naricilla. Media $1 \mathrm{~m}$ y 70 centímetros. Su cuerpo estaba todo él muy bien formado.

Este tipo de intervencionismo no es intencionado porque se debe normalmente al descuido o a los desconocimientos del traductor. Tampoco parecen ser intencionadas las frecuentes omisiones de partes de textos originales (Tilgungen), mayoritariamente 
injustificadas, y las aclaraciones extratextuales (metasprachliche Erklärungen), en ocasiones poco aclaradoras.

Como ejemplo del primer caso, llama poderosamente la atención la omisión del párrafo final en la traducción española de Jim Knopf und der Lokomotivfiuhrer (1960) (Jim Botón y Lucas el maquinista (1962)) de Michael Ende:

PS: Lieber Lukas! Nun hat Jim also erfahren, dass ich nicht seine wirkliche Mutter bin. Vielleicht ist es ja Frau Mahlzahn, an die damals das Paket adressiert war. Ich bin sehr traurig, aber andererseits freue ich mich für meinen kleinen Jim, wenn er jetzt seine richtige Mama findet. Ich hoffe nur, sie ist nicht allzu böse auf mich, weil ich ihn bei mir behalten habe. Bitten Sie doch Frau Mahlzahn, dass der Junge nach Lummerland zu Besuch kommen darf, damit ich ihn nochmal sehen kann. Oder vielleicht hat sie Lust mit herzukommen? Dann würde ich sie auch kennenlernen, das wäre das allerbeste. Und nicht wahr, Sie sorgen schon dafür, dass Jim sich nicht in Gefahr begibt? Er ist so ein leichtsinniger kleiner Bub.

Herzliche Grüsse!

Frau Waas

Puede parecer de poca relevancia, pero es un epílogo donde se confirma al lector que Frau Waas efectivamente no es la madre de Jim, y que posiblemente lo es Frau Mahlzahn, un asunto que todavía queda por descubrir. Existen dieciséis reediciones posteriores a esta traducción, "completamente revisadas", según la editorial, pero ninguna de ellas ha rectificado esta omisión.

La aclaración extratextual o metalingüística se emplea en forma de nota a pie de página o de glosarios que acompañan el texto. Además de interrumpir la lectura, no siempre aportan datos aclaratorios y, a veces, hasta desconciertan al joven lector, como es el caso de la traducción de la obra Das doppelte Lottchen de Erich Kästner (Las dos Carlotas), donde se mencionan platos habituales en la gastronomía alemana. La traductora mantiene el término alemán y lo explica en una nota a pie de página que, en realidad, necesitaría una nota explicativa diferente:

„Aber Kalbsschnitzel und Gulasch wären mir lieber!"

„Aunque yo, desde luego, hubiera preferido bistecs de ternera y gulasch" (1).

(1) Típico plato húngaro, una especie de carne estofada muy picante.

En su obra autobiográfica Maikäfer, flieg (1973), Christine Nöstlinger emplea una gran cantidad de abreviaturas y términos relacionados con el nacionalsocialismo que la traductora intenta aclarar utilizando notas a pie que, en ocasiones, son confusas porque se citan en alemán sin explicación:

'Völkischer Beobachter' ...." (1)

(1) 'Völkischer Beobachter' - Tageszeitung der NSDAP seit 1923

Traducción:

'Observador del Pueblo' ...." (1)

(1) Völkischer Beobachter: 'Observador del Pueblo', diario muy tendencioso (N. del A.) 
No se entiende la cita en alemán en la nota española y tampoco es explicativo el adjetivo "muy tendencioso". Realmente hubiera sido más claro decir que se trata de un "diario nazi". La otra apostilla que llama la atención es "N. del A." que obviamente no se refiere a Nöstlinger sino a la traductora y así debería figurar'.

Sea cual sea el grado de manipulación, lo que es inexcusable en el traductor de LIJ es la incoherencia. Estos desajustes seguramente se evitarían si la editorial procediese a revisiones más rigurosas de las traducciones. Suceden normalmente cuando hay juegos de palabras, referencias culturales infantiles y nombres propios.

En el libro Liebe Susi, lieber Paul de Nöstlinger, la protagonista se inventa un juego de palabras con el objetivo de abreviar la escritura normal porque "so geht das Schreiben viel schneller", (p. 63), sustituyendo partes de palabras por símbolos matemáticos y números:

Ich bin wieder ganz ges+!

Bald ist es N8!

Ich •e ein Bild!

Darauf ist ein Baum mit vielen 2gen.

Neben ihm steht eine 1le. Die hat ein Fahrrad.

Aber in den Ra3fen ist keine Luft.

Es prácticamente imposible traducir estos juegos de palabras aplicando los mismos símbolos. La traducción en castellano utiliza una especie de adivinanza empleando letras, números y dibujos para llegar a la palabra que representan, pero con un resultado contrario a lo que quería Susi: en lugar de abreviar, las frases resultan ser más largas:

EEEtoy otra vez bien.

Pronto será de $\mathrm{n}+8$-o+e.

Estoy pintan $\delta$ un dibujo.

Hay un árbol con muchas rat.

A su lado está 1-o hada. TiN una bicicleta.

Pero los neumáticos no están hincha2.

Aparte de que complican la lectura, estas adivinanzas también dificultan la escritura porque hay que inventárselas y luego descifrarlas ya que constan de más letras que la palabra resultante. La incoherencia se produce precisamente cuando la protagonista afirma que "así se escribe más deprisa".

Incoherentes son también algunas partes de la traducción de Das doppelte Lottchen de Erich Kästner. Llama la atención que, a pesar de que la traducción española se titula Las dos Carlotas, ninguna de las gemelas lleva el nombre Carlota (excepto una vez) sino Luisa

\footnotetext{
${ }^{4}$ Véase M. Fischer, "Hinterhof und Powidltatschkerln. Kulturspezifika bei der Übersetzung von Kinderliteratur", Grenzgänge, Nr. 6, 1999
} 
y Lotte o Lottchen. Empleando tres nombres diferentes para las niñas y dos para la madre (Luisa Carlota y, con más frecuencia, Luiselotte) se produce una gran confusión porque se mezclan varios nombres para una misma persona:

Und weil Mutti Luiselotte heißt, haben sie das eine Kind Luise und das andere Lotte getauft. (p. 39)

En la versión española, la traductora modifica los nombres arbitrariamente y sin ningún motivo fundado:

Entonces tuvieron dos niñas, y como mamá se llama Luisa Carlota, bautizaron a una de ellas con el nombre Luisa y a la otra con el de Carlota. (p. 37)

Bueno, ¿quién de las dos es Luisa Palffy y quién Lotte Körner? - ¡Eso no vamos a decirlo nosotras! - advierte una de las Carlotas mientras le guiña un ojo a la otra. (p. 37)

Luiselotte, tu has hecho de una dócil criatura una ama de casa ... (p. 90)

Hasta este punto se han podido observar diversas formas de intervencionismo intencionado y no intencionado en las traducciones de obras de LIJ alemana al castellano. Aún más evidente es el intervencionismo del mediador (normalmente intencionado) cuando los motivos de la manipulación son de carácter sociolingüístico e histórico. Este es el caso de las comunidades autónomas bilingües donde coexisten dos lenguas en competición. Para impulsar la más débil, que es la autóctona, los gobiernos autónomos establecen a través de la política lingüística determinadas opciones a su favor.

\section{POLÍTICA LINGÜÍSTICA Y EDITORIAL DE LA COMUNIDAD RECEPTORA.}

En Galicia, como en las otras comunidades bilingües donde compiten dos lenguas cooficiales, el sistema lingüístico y literario gallego, debilitado durante la época franquista, necesitaba de un estímulo riguroso y planificado para consolidarse como un sistema fuerte. En el año 1983, entra en vigor la Ley de Normalización Lingüística con la que el gallego se introduce en los colegios como una asignatura obligatoria y se convierte, con el paso del tiempo, en la lengua oficial del sistema escolar gallego. La falta del material didáctico y de libros de lectura en gallego obliga a buscar soluciones rápidas e inmediatas para responder a la demanda existente. Ya que la producción propia es escasa y lenta e incapaz de suplir la ausencia de literatura en gallego para las edades escolares, la solución se encuentra en la traducción, de gestación más rápida que la obra original.

Es de subrayar que la mayor parte de las traducciones todavía hoy se inscriben en este marco normalizador del idioma, estando amparadas por las instituciones públicas. La Xunta de Galicia, por ejemplo, tiene un convenio con las editoriales gallegas comprometiéndose a comprar un $10 \%$ de la edición, hasta un máximo de 300 ejemplares, con lo cual hace que las editoriales se animen a desarrollar proyectos en gallego. Asi pues, muchas traducciones surgen por el apoyo institucional y por la presión de la intelectualidad gallega y no por la repercusión social en forma de la demanda que tengan. Al decidir realizar traducciones al gallego, se está pensando más en la lengua que se va a enriquecer con ellas que en los potenciales lectores. Las traducciones literarias al gallego tienen otro factor negativo que es el económico porque un libro traducido es un libro caro, puesto que a la compra de 
derechos de autor hay que añadirle el salario del traductor $\mathrm{y}$, en ocasiones, los derechos sobre la traducción. Precisamente, siguen siendo los condicionantes económicos los que llevan a muchas editoriales gallegas dependientes de casas editoras españolas a emprender traducciones de obras extranjeras traducidas previamente al español, dado que cuando la editorial madre compra los derechos de una obra lo hace casi siempre con la cláusula "para todo el territorio español", logrando así muy hábilmente un coste mínimo para la edición de traducciones a las diferentes lenguas comunitarias, incrementando al mismo tiempo las expectativas de venta.

Las versiones-puente, mediante las cuales la obra no entra directamente en las lenguas de las diferentes autonomías desde su idioma original, sino que lo hace a través de una traducción intermedia al castellano, siguen siendo desgraciadamente una práctica habitual de muchas editoriales que comprometen gravemente la calidad de los textos resultantes, importando errores y calcando artificialmente el estilos.

Aparte de los condicionantes económicos, que conducen a la creación de versionespuente, la politica lingüística de la comunidad receptora y la presión de la institución son otros dos condicionantes que influyen en el grado de intervencionismo intencionado, hasta tal extremo que se crean versiones totalmente adaptadas a la cultura de llegada, donde todos los referentes de una cultura diferente se adaptan a la propia. En estos casos puntuales, la traducción a la lengua autóctona sirve únicamente como proyección y potenciación del propio bien cultural.

Uno de los ejemplos más llamativos es la "traducción" al catalán de Wir pfeiffen auf den Gurkenkönig, 1972 (Cop d'escombra al rei cogombre, 1992) y Der Zwerg im Kopf, 1989 (Follet fiact al cap, 1995) de C. Nöstlinger. En ambas traducciones, todo está adaptado a Cataluña: las acciones, los nombres propios de personas y lugares, así como las referencias culturales. Incluso se mantiene la diferenciación entre los nombres austriacos y los extranjeros, empleando la traductora en su versión los nombres catalanes para los austriacos y los castellanos para los extranjeros. Son libros que se prestan fácilmente a este tipo de adaptaciones pues tratan temas universales, como la democracia, solidaridad o tolerancia, y sus acciones se desenvuelven en tiempos y lugares indeterminados.

También los cuentos de Grimm han sufrido traducciones domesticadas. En el prólogo de Os contos de Grimm (1991), el traductor gallego, que aparece bajo el pseudónimo Eubensei, subraya que el libro debe servir para aprender un gallego auténtico y correcto. Aparte de las referencias culturales, llama la atención la adaptación de nombres tan emblemáticos como Hänsel und Gretel que se convierten en Cibrao e Graciña, o Dörnröschen en Zarzarrosa. Hasta las ilustraciones reflejan la cultura autóctona, porque Cibrao e Graciña visten el típico traje gallego. No menos llamativa es una traducción de los mismos cuentos al vascuence. Alejandro Larrakoetxea, "Leogaldi", bautiza Hänsel und

\footnotetext{
${ }^{5}$ Véase M. Saalbach, „Die Seejungfrau in der Sardinenbüchse von Gudrun Pausewang in baskischer Übersetzung: eine kritische Untersuchung“, en: V. Ruzicka Kenfel, op.cit.; Véase E. Huber, Análisis de la traducción de Liebe Susi! Lieber Paul! al euskara, en: V. Ruzicka, L. Lorenzo, Estudios críticos de traducción de literatura infantil y juvenil. Análisis de las traducciones de obras inglesas y alemanas a las cuatro lenguas oficiales de España, Oviedo, Septem, 2002
} 
Gretel en Yulitxo ta Libetxo, Schneewittchen en Edur-zuritzo y Dornröschen en Larrosagorri $^{6}$.

En las adaptaciones parciales, que afectan a segmentos concretos, el traductor efectúa modificaciones que, en el caso de comunidades con conflictos lingüísticos, servirán para evidenciar la postura del mediador a favor de la lengua autóctona, más débil y con necesidad de recuperación. La amenaza que supone el sistema lingüístico más fuerte, el castellano, impulsa al traductor a adoptar diferentes estrategias para fortalecer el sistema en peligro.

Uno de los procedimientos estratégicos es el empleo de elementos diferenciales que no coinciden con la lengua con la que compite. El traductor recurre a nombres, términos y referencias culturales gallegos que difieren del castellano. En el siguiente ejemplo, citado de Max und Moritz (Wilhelm Busch, 1865) se menciona "Sauerkohle" que equivaldría al término "chucrút", adoptado directamente del francés y poco habitual pero aceptado en la lengua castellana. El traductor gallego, sin embargo, aprovecha la oportunidad para introducir "repolo", un ingrediente muy propio de la gastronomía gallega:

"Dass sie von dem Sauerkohle

Eine Portion sich hole" (p. 15)

Max e Moritz (2001):

"Vai oufana co cazolo

á procura de repolo" (p. 17)

Max y Moritz (1990):

"La viuda sale a buscar

chucrút para acompañar" (p. 19)

También en el siguiente ejemplo (Struwwelpeter, Heinrich Hoffmann, 1844), el traductor se distancia de la versión castellana y emplea los elementos de su propia cultura manteniendo a la vez la carga semántica del original, porque Lämpel alude a "Lampe" y al tratarse de un maestro, es alguien que transmite la sabiduría o que ilustra. Mientras la traducción castellana $($ Lemplo) impide esta interpretación, la gallega $($ Misto $=$ Cerilla $)$ conserva el efecto semántico:

Struwwelpeter (1844):

Drauf so sprach Herr Lehrer Lämpel:

„Dies ist wieder ein Exempel!“ (p. 36)

Pedro Guedellas (2001):

Deu don Misto en sentenciar:

${ }^{6}$ Véase también J.M. López Gaseni, "La literatura juvenil traducida al euskera", Revista de Psicodidáctica, Nr. 8, 1999. 
„¡Mal andar trae mal parar!“” (p. 59)

Pedro el greñoso (1980):

Añadió Lemplo, el maestro:

- ¡Qué triste ejemplo fue el vuestro! (p. 62)

Otra de las estrategias que contribuye al proceso de normalización y normativización lingüísticas del idioma minoritario es la inclusión de componentes paremiológicos de la lengua, en forma de refranes o frases hechas, como segmentos añadidos y no existentes en el texto original. Por ejemplo, el traductor al gallego de los siguientes versos extraídos de Max und Moritz (Wilhelm Busch, 1865) incorpora al principio de una de las travesuras dos versos nuevos, no presentes ni en el original ni en la traducción al castellano. El objetivo es aludir a la fiesta de San Xoán, una de las más populares en Galicia y, además, hacer saber al lector que "o mes de San Xoán" es el mes de junio en lengua gallega:

"Jeder weiss, was so ein Mai=

Käfer für ein Vogel sei,” (p. 32)

Max e Moritz (2001):

"Á tardiña, por San Xoán,

Voa un becho moi cornán,

évos un escaravello

de carácter moi besbello." (p. 36)

Max y Moritz (1990):

"Entre las hierbas y el tallo,

escarabajos de mayo." (p. 39)

Un ejemplo más del elemento paremiológico en la traducción se descubre en el verso arriba citado de Struwwelpeter: "Dies ist wieder ein Exempel", que se traslada a la versión gallega con el refrán popular: "Mal andar trae mal parar" y no se neutraliza como lo hace la traducción castellana, prácticamente literal: "Que triste ejemplo fue el vuestro".

Presionado por las instituciones impulsoras de la política lingüística y por miedo a que lo acusen de mezclar en el gallego estructuras del castellano, el traductor recurre a la neutralización de aspectos creativos, conservando los elementos de su propia cultura y distanciándose a la vez de los términos castellanos. "O mago" y, sobre todo, "o feiticeiro" son figuras propias de los cuentos populares gallegos que el traductor emplea como equivalencia al "Nikolas", una figura tradicional germánica que premia a los niños buenos y castiga a los malos. La solución castellana "Coco", sin embargo, no parece la más acertada porque los niños asocian esta figura con una persona que provoca miedo:

Struwwelpeter (H. Hoffmann, 1844):

"Da kam der große Nikolas

mit seinem großen Tintenfaß". (p. 9) 
"Der Niklas wurde bös und wild

du siehst es hier auf diesem Bild!" (p. 10)

Pedro Guedellas (2001):

"Chega entón un feiticeiro

cargado co seu tinteiro.” (p. 20)

"Mirade o mago anoxado

no debuxo que está ó lado.” (p. 22)

Pedrito el greñoso (1980):

"Al Coco el hecho disgusta,

esta burla no le gusta." (p. 12)

"El Coco, ya enfurecido

por los pelos ha cogido." (p. 13)

Otro procedimiento diferencial que adoptan los traductores se manifiesta en el tratamiento de las variaciones lingüísticas y estilísticas. Buscan la oportunidad de emplear variedades lingüísticas locales, cuando en el texto original aparecen el dialecto, la jerga o el coloquialismo. Nöstlinger suele utilizar austriacismos y la jerga juvenil que sirven al traductor gallego para introducir variantes geográficas de la lengua autóctona, como por ejemplo, la "gheada" en el caso siguiente:

Stundenplan (C. Nöstlinger, 1975):

"Man kann do net mit'n Kopf durch die Wand rennen." (p. 145)

"Bleibt's nur hocken." (p. 145)

Horario de clase (1998):

"Un non pode ir peghándose croques contra as paredes." (p. 162)

"Seghe sentada." (p. 162)

Horario de clase (1992):

"No se puede ir dándose de cabeza contra la pared." (p. 165)

"Sigue sentada." (p. 165)

La existencia de diferentes modelos estilísticos en la lengua origen y la lengua meta posibilita intervenir a los mediadores a favor de esta última, adaptando la traducción a los modelos existentes en la cultura de llegada. En el caso de las traducciones al gallego, uno de los marcadores de estas variantes estilísticas se observa en la utilización excesiva de la forma diminutiva, una particularidad de la LIJ gallega y de la lengua coloquial:

Feuerschuh und Windsandale (U. Wölfel, 1961)

Tim der Dicke

Geht über die Brücke (p. 11)
Seid vorsichtig, ihr beide! (p. 26)

Was für ein kleiner Bahnhof! (p. 30) 
Zapatos de lume e sandalias de vento (1990)

Tim a vaquiña

vai pola pontiña (p. 10)
¡Tende moito coidadiño! (p. 21)

¡Qué estación máis pequerrechiña! (p. 25)

Zapatos de fuego y sandalias de viento (1997)

Tim el gordo

¡Sed muy precavidos! (p. 27)

Se paseó por un puente (p. 14)

¡Qué estación más linda! (p. 31)

Hay modelos estilísticos que todavía no tienen cabida en los libros infantiles gallegos, como por ejemplo, la intervención de un narrador omnisciente en algunos momentos clave de la narración, estableciendo un diálogo con el lector. Al dirigirse directamente al receptor, el narrador detiene su lectura y le sugiere una breve reflexión. Mientras que en la literatura en lengua castellana este marcador no se evita, los mediadores gallegos (en el caso siguiente, la decisión fue del editor) prefieren no introducir el modelo innovador:

Oh, wie schön ist Panama (Janosch, 1978)

"Aber du weißt schon, was das für ein Wegweiser war. Na? Genau." (p. 43)

\section{$(-\cdots-)$}

"Du meinst, dann hätten sie doch zu Hause bleiben können? Du meinst, dann hätten sie sich den weiten Weg gespart? O nein, denn sie hätten den Fuchs nicht getroffen, und die Krähe nicht. Und sie hätten den Hasen und den Igel nicht getroffen, und sie hätten nie erfahren, wie gemütlich ein schönes weiches Sofa aus Plüsch ist." (p. 48)

Qué bonito es Panamá (2001)

"Pero a qué tu ya sabes de qué poste se trataba. ¿A ver? Exacto." (p. 42)

(--.--)

“¿Piensas que se hubieran ahorrado el camino? ¡Oh, no! Porque no se hubieran encontrado al zorro ni a la corneja. Y no se hubieran encontrado ni a la liebre ni al erizo y nunca hubieran sabido lo cómodo y blando que es un sofá de terciopelo." (p. 47)

¿Que bonito é Panamá! (2001)

E bailaron de alegría brincando aquí e acolá. (p. 38)

E, se no chegan atopa-la lebre e o ourizo, nunca saberían o cómodo que se está nun sofá de felpa brandiño. (p. 45)

\section{Conclusiones.}

El relativamente alto grado de intervencionismo en las traducciones de LIJ, tanto intencionado como no intencionado, es la consecuencia esperable de una situación que los investigadores de este campo llevamos denunciando desde hace bastante tiempo: en primer lugar, la mayoría de las editoriales no incluyen procesos de revisión de las traducciones y, 
si lo hacen, inciden sólo en la corrección gramatical de los textos, sin tener en cuenta en ningún momento el texto original. Si las traducciones estudiadas en el presente trabajo hubiesen pasado por el filtro de un segundo traductor-revisor, probablemente se hubiesen subsanado desajustes y corregidos errores o incoherencias. En segundo lugar, para que la traducción de LIJ alcance su plena madurez con un nivel de calidad incuestionable, debe liberarse de la influencia permanente de las instituciones y de un mercado impulsado casi exclusivamente por los programas de lectura escolares. En las comunidades bilingües es además necesario seguir luchando para acabar con las traducciones a partir de versionespuente cuyo efecto es a veces justo el contrario al deseado: escaso número de ventas, motivado por una política editorial inapropiada porque no es poco habitual que se publique antes la obra en castellano y luego, meses más tarde, en gallego, con lo cual cuando ésta última sale al mercado, la mayoría de los gallegos ya la han leído en el castellano. Es además de mencionar que todavía muchos gallegos siguen prefiriendo la lectura en castellano.

Por último, creemos que los ejemplos presentados demuestran la importancia de la preparación del traductor que desempeña el doble papel de coautor y de mediador entre dos culturas, un papel que ya no hace falta reivindicar. Lo que todavía sigue siendo una necesidad es la creación de parámetros evaluativos. Sería preciso establecer filtros que valoren y encarrilen el grado de intervencionismo de los traductores, que posibilitarian establecer un indicio o un límite de aceptabilidad que decida hasta qué punto la intervención del traductor es necesaria o simplemente tolerable y a partir de qué punto se convierte en manipulación, entendida ya desde una óptica peyorativa y menospreciada.

\section{REFERENCIAS BIBLIOGRÁFICAS.}

EWERS, H. H., Literatur für Kinder und Jugendliche. Eine Einführung, München, Fink, 2000.

FISCHER, M., "Hinterhof und Powidltatschkerln. Kulturspezifika bei der Übersetzung von Kinderliteratur“", Grenzgänge, Nr. 6, 1999

FISCHER, M, "Konrad, Pinocchio y Edipo: la intertextualidad en la tradución de la literatura infantil", en: L. Lorenzo, A. Pereira, V. Ruzicka (ed.), Contribuciones al estudio de la traducción de literatura infantil y juvenil, Madrid, CIE. Dossat 2000, 2002, p. 43-69.

HUBER, E., "Análisis de la traducción de Liebe Susi! Lieber Paul! al euskara", en: V. Ruzicka, L. Lorenzo, Estudios críticos de traducción de literatura infantil y juvenil. Análisis de las traducciones de obras inglesas y alemanas a las cuatro lenguas oficiales de España, Oviedo, Septem, 2003.

LÓPEZ GASENI, J.M., "La literatura juvenil traducida al euskera", Revista de Psicodidáctica, Nr. 8, 1999

MARCELO WIRNITZER, G., "Verschiedene Arten von Domestizierung bei Übersetzungen von Büchern von Christine Nöstlinger ins Spanische", en: V. Ruzicka Kenfel, Kulturelle Regionalisierung in Spanien und literarische Übersetzung. Studien 
zur Rezeption deutschsprachiger KJL in den zweisprachigen autonomen Regionen Katalonien, Galicien und Baskenland, Frankfurt a.M., Peter Lang, 2002, p. 97-109.

SAALBACH, M. „Die Seejungfrau in der Sardinenbüchse von Gudrun Pausewang in baskischer Übersetzung: eine kritische Untersuchung“, en: V. Ruzicka Kenfel, Kulturelle Regionalisierung in Spanien und literarische Übersetzung. Studien zur Rezeption deutschsprachiger KJL in den zweisprachigen autonomen Regionen Katalonien, Galicien und Baskenland, Frankfurt a.M., Peter Lang, 2002. 